\title{
Craniometrical evidence for population admixture between Eastern and Western Eurasians in Bronze Age southwest Xinjiang
}

\author{
TAN JingZe ${ }^{1,2}$, LI LiMing ${ }^{1}$, ZHANG JianBo $^{1}$, FU WenQing ${ }^{1}$, GUAN HaiJuan ${ }^{2}$, AO Xue ${ }^{2}$, \\ WANG LingE ${ }^{1}$, WU XinHua ${ }^{3}$, HAN KangXin ${ }^{3}, \mathrm{JIN} \mathrm{Li}^{1,2} \&$ LI Hui ${ }^{1,2^{*}}$ \\ ${ }^{1}$ Key Laboratory of Contemporary Anthropology (Ministry of Education), School of Life Sciences, Fudan University, Shanghai 200433, China; \\ ${ }^{2}$ Shanghai Society of Anthropology, Shanghai 200433, China; \\ ${ }^{3}$ Institute of Archaeology, Chinese Academy of Social Sciences, Beijing 100710, China
}

Received March 23, 2012; accepted May 11, 2012; published online October 11, 2012

\begin{abstract}
Xinjiang, the most northwest provincial administrative area of China, was the area where the oriental people met the occidental. The populations in Xinjiang exhibit very high genetic diversity. Previous study revealed that the eastern Xinjiang populations of the Bronze Age were mixed by the Eastern and the Western Eurasians. However, few studies have been performed to reveal when the population admixture started and how far to the west it reached. In this paper, we studied 148 craniofacial traits of 18 skulls from the Bronze Age Liushui graveyard in Khotan (Keriya County) in the southwest of Xinjiang. Seventeen craniometrical parameters of the Khotan samples were then compared with those of other ancient samples from around Xinjiang using dendrogram cluster analysis, principal components analysis, and multidimensional scaling. The results indicated that population sample of Liushui graveyard was mixed by the Western and Eastern Eurasians with about $79 \%$ contribution from the east. Therefore, we demonstrated that population admixture between east and west Eurasia can be traced back to as early as $1000 \mathrm{BC}$ in southwest Xinjiang.
\end{abstract}

craniometry, morphology, population admixture, Khotan Kingdom, Bronze Age

Citation: Tan J Z, Li L M, Zhang J B, et al. Craniometrical evidence for population admixture between Eastern and Western Eurasians in Bronze Age southwest Xinjiang. Chin Sci Bull, 2012, 57: 299-306, doi: 10.1007/s11434-012-5459-6

Xinjiang is the most northwest provincial administrative area of China, locating between East Asia and Central Asia. The modern populations of Xinjiang were found to have both characters of Eastern and Western Eurasians since the very beginning of the relevant anthropological studies [1]. Both physical anthropology [2] and molecular anthropology [3-5] revealed that indigenous Xinjiang people exhibit intergradations between the oriental and occidental people. Most populations are more similar to the oriental people genetically. Even the Uyghur, a population with the lowest proportion of oriental genetic contribution, has at least $60 \%$ lineages from the orient [5]. The characters of intergradations might have come from either of two processes: (1) admixture between two different populations, or (2) ances-

*Corresponding author (email: lhca@fudan.edu.cn) tral population deriving into populations in both sides. According to the genomic analyses, the Xinjiang populations are not ancestor of the other Eurasian populations, but admixed populations [6]. Therefore, our question is how early the admixture happened, and where.

The early Xinjiang people were regarded as a different "race" from the East Asians by most central China ancient people [7]. Archaeological findings revealed that Bronze Age residents of Xinjiang were very similar to the western Eurasians [8]. Therefore, it was widely accepted that the East Asians did not influence the early Xinjiang people much during the Bronze Age. However, recent studies of the DNA from the Bronze Age Xinjiang Mummies led to very different conclusions. DNA analyses revealed pronounced eastern proportions in the genetic structures of the ancient mummies from several important archaeological 
sites in eastern Xinjiang, including Qumul [9], Kroran [10], Charchan [11], etc. These results proved that the East Asians had at least arrived in eastern Xinjiang at the Bronze Age. However, archaeological studies suggested that the ancient people of the western Xinjiang, the Saka, were different nation from the eastern Xinjiang Tocharians [8]. Therefore, the genetic admixture in western Xinjiang of the Bronze Age is necessary to investigate. Recently, we studied the cranial characters of a population sample of Bronze Age Khotan Kingdom from Keriya County in southwest Xinjiang, and found apparent population admixture between Eastern and Western Eurasians.

This population sample was found in 2002 from a Bronze Age graveyard near Liushui Villiage, Achan Township, Keriya County, Hotan Prefecture, Xinjiang Uygur Autonomous Region, and was in the Silk Road (Figure 1). The excavation was finished in 2005. Fifty-two tombs were found. The human remains from the tombs were dated by ${ }^{14} \mathrm{C}$ to $2950 \pm 50$ year before present [12]. That is to say, this graveyard, the Liushui graveyard, is the oldest site found in southwest Xinjiang.

\section{Materials and methods}

\subsection{Samples and craniometrical standards}

We excavated 21 human skeletons from Liushui graveyard of Khotan in 2003. According to craniometrical standard, they were 12 males, eight females, and one minor. Eighteen adults had intact skulls. We analyzed 31 observational features and 88 metrical items on these skulls, and calculated 29 morphologic indices (Table S1). We used the international standard of craniometry [13]. To compare our sample to those from Central Asia and East Asia, we studied the craniometrical standards of Russia [14], China [15], and
Japan [16], and did not find them different from the international standard.

\subsection{Clustering analyses}

The craniometrical results (17 indices) of Khotan were compared with those data from the Bronze Age samples from Northwestern Asia, Central Asia [17,18], Xinjiang [19-28], and Central China [29-32]. Multidimensional scaling analysis (MDS) and principal component analysis (PCA) were used in population comparison. The first eight principal components (94.2\% of variance) were transformed by Pearson's $r$ into genetic distances, and a dendrogram by Unweighted Pair Group Method with Arithmetic mean (UPGMA tree) was drawn based on these distances. As cranial features show much more variations among male samples than among female samples, previous studies usually only used data of males in clustering analyses. Our analyses also compared males only.

\subsection{Admixture analysis}

We developed a method to explore the population structures among our metric data. The method is to reveal the contribution rates of two presumed ancestral populations from Eastern and Western Eurasians to the Xinjiang populations based on the mean values of 17 traits of each population.

Eastern ancestral population is represented by ' $A 1$ ' and Western ' $A 2$ '. Let $C_{i t}$ denote the mean values of the group $i$ and the trait $t$ in dataset, and $\omega_{i}$ represent the contribution rate of $A 1$ to group $i$ as well as $1-\omega_{i}$ to $A 2$. The function of residual error can be built

$$
\text { Residual error }=\sum_{i=1}^{30} \sum_{t=1}^{17}\left[C_{i t}-\omega_{i} \times A 1_{t}-\left(1-\omega_{i}\right) \times A 2_{t}\right]^{2},
$$

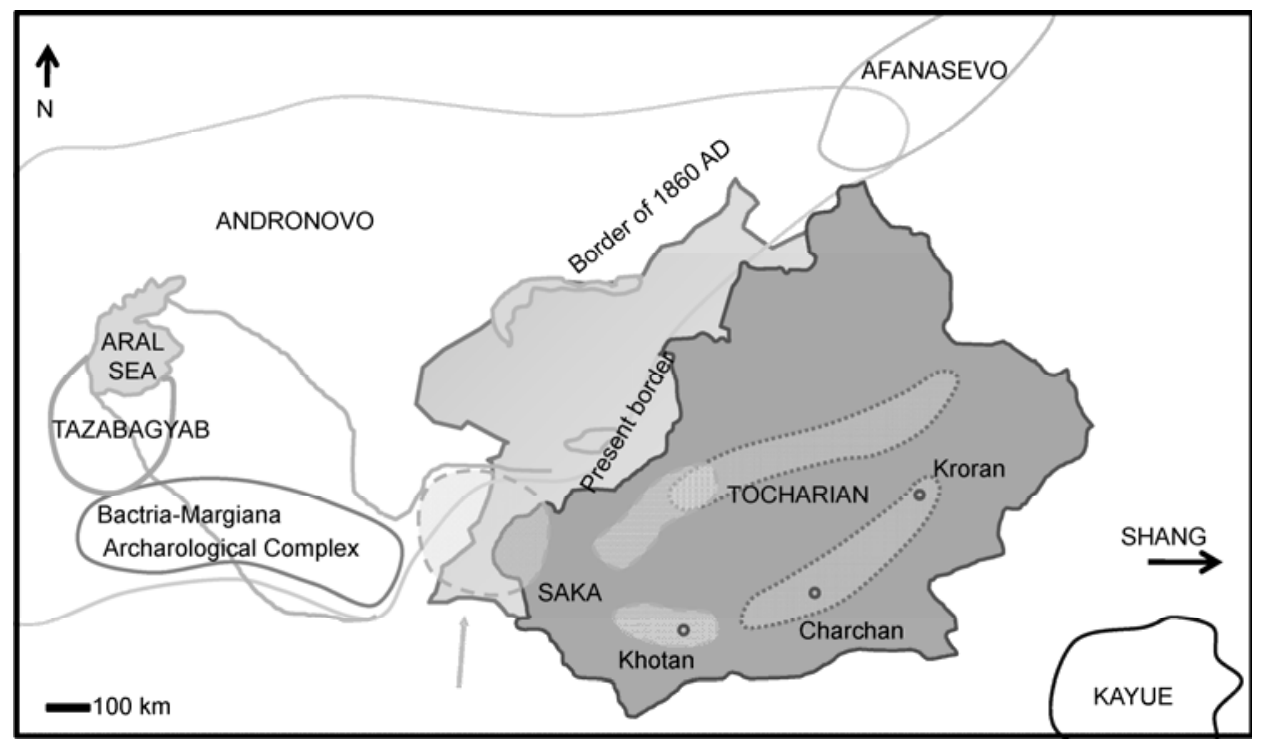

Figure 1 Distribution of Khotan in Xinjiang and the archaeological cultures around. 
where $A 1_{t}$ and $A 2_{t}$ are the mean values of trait $t$ of presumed ancestral populations $A 1$ and $A 2$, respectively. Note that both $A 1_{t}$ and $A 2_{t}$ are unknown and two group sets point to Eastern and Western Eurasians are distinct in our dataset, thus we let the mean of these two sets be the estimates of $A 1_{t}$ and $A 2_{t}$, respectively.

Our aim is that find the most possible set of $\omega_{i}$ which minimize the function of residual error. Note that $\omega_{i}$ is independent to $\omega_{j}$ for $i \neq j$, the set of $\omega_{i}$ has sole solution

$$
\omega_{i}=\frac{\sum_{t}\left[\left(A 2_{t}-C_{i t}\right) \times\left(A 2_{t}-A 1_{t}\right)\right]}{\sum_{t}\left(A 2_{t}-A 1_{t}\right)^{2}} .
$$

The solution of the function above may be negative or greater than 1, and according to the property of the function, it should be corrected by letting negative value to be 0 and the value greater than 1 to be 1 .

The data standardized by original data was used in this analysis.

\section{Results}

\subsection{Craniofacial features and ancestry identification for individuals}

In our samples, 11 males, seven females, and a child have intact skulls. We collected craniometrical data of these 19 skulls (Table S1). As features of children are not fully developed, we excluded the data of the child skull from our analyses hereafter.

Populations from different geographic regions of the world have apparently different skull features $[7,17,18]$, especially the shapes of orbital cavity and nasion. We observed these features on our samples, and found that some samples were similar either to the Eastern Eurasians or to the Western Eurasians, while some had characters of both sides, which suggested admixture between Eastern and Western Eurasians (Figure 2). We calculated the allele frequencies of 32 features in our samples (Table S2), and compared 12 features with ancestry identification characters with the reference western and eastern populations. Among the 12 features, seven features of most Khotan samples were western types, two features were eastern types, and three features were different in ancestry identification between males and females (Table 1). Therefore, the observation features of the Khotan samples were mostly western types, which made this population sample more like Western Eurasians.

Some metrical data can be transformed into morphological indices of skulls. We also calculated these indices in our samples and classified the indices of the samples into grades (Table S3). Among these indices, four items are different between Eastern and Western Eurasians. Most Khotan samples had western types for these four items, which was consistent with the observational features. Totally, the Khotan samples were more like Western Eurasians for the observa-

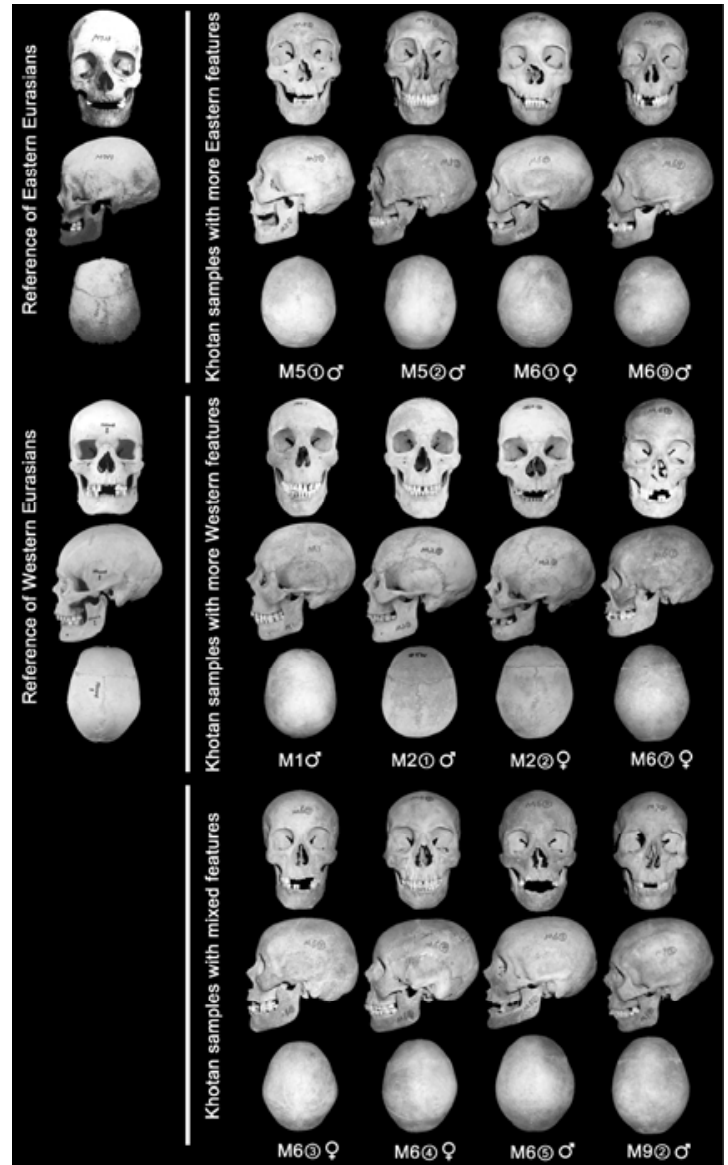

Figure 2 Some of the Khotan skulls compared to the referential samples of Eastern and Western Eurasians. Sex information is marked by $q$ or $\sigma^{\star}$ under each skull.

tional features of individual samples.

\subsection{Population comparison and ethnic classification}

It is imprecise to judge the origin of a population only by observing individual samples. Instead, many software programs can analyze the population data to assess the distances among populations. Here, we performed multiple methods (MDS and PCA) to estimate the distances between Khotan and other neighboring populations and influences from the Eastern and Western Eurasians.

We included 17 metrical items in the analyses (Table S4). These items are key items normally used in the craniometrical analyses, including sizes and angles of cranium, face, orbita, nose, zygoma, etc. Thirty populations from Xinjiang, East China, Central Asia, Siberia, and East Europe were included in the analyses, and were classified into three groups: 1, populations in Xinjiang (within the border of Xinjiang before $1860 \mathrm{AD}) ; 2$, populations to the west of Xinjiang; and 3, populations to the east of Xinjiang. Distances among the populations were plotted in the maps (Figure 3).

In the MDS map (Figure 3(a)), the populations from the 
Table 1 Craniofacial features of Khotan samples compared to those of the typical Eastern and Western Eurasians

\begin{tabular}{|c|c|c|c|c|}
\hline \multirow{2}{*}{ Item } & \multirow{2}{*}{ Western } & \multirow{2}{*}{ Eastern } & \multicolumn{2}{|c|}{ Khotan } \\
\hline & & & Most individuals & More like \\
\hline Superciliary arch & Distinct & Weak & Distinct $̋ /$ Weak 우 & Western § / Eastern 우 \\
\hline Glabella projection & Strong & Weak & Strong $\widehat{o} /$ Light 우 & Western $\widehat{\jmath} /$ Eastern 우 \\
\hline Orbit shapes & Rectangle/Orthorhombic & Circular/Ellipsoid & Orthorhombic & Western \\
\hline Orbital inclination & Forward oblique & Backward oblique & Backward oblique & Eastern \\
\hline Nasion depression & Deep & Shallow/None & Deep & Western \\
\hline Types of nasal roof & Straight/Convex-concave & Straight/Concave & Convex-concave & Western \\
\hline Piriform aperture & Pear-shaped & Heart-shaped & Pear-shaped $\lesssim$ /Heart-shaped 우 & Western $\lesssim /$ Eastern 우 \\
\hline Canine fossa & Deep & Shallow & Shallow & Eastern \\
\hline Zygomatic shape & Oblique & Blunt & Oblique & Western \\
\hline Malar jnt & Distinct & Light & Distinct & Western \\
\hline Palate shape & C shape & Parabola & C shape & Western \\
\hline Shovel incisor & None/Weak & Significant/Moderate & None & Western \\
\hline Total profile angle & Orthognathous & Prognathous & Orthognathous & Western \\
\hline Nasal index & Leptorrhiny & Mesorrhiny/Chamaerrhiny & Leptorrhiny ô/Mesorrhiny 우 & Western $ð$ /Eastern 우 \\
\hline Orbital index & Chamaeconchy & Mesoconchy/Hypsiconchy & Hypsiconchy $\widehat{o} /$ Mesoconchy 우 & Eastern \\
\hline Simotic index & Protrudent & Weak & Protrudent & Western \\
\hline
\end{tabular}

same geographic region were clustered closely, i.e., the Eastern Eurasians were in the left, the Western Eurasians were in the right, and the Xinjiang populations, including the Huns, Wusun, and Saka from western Xinjiang, were in the middle. This distribution indicated that the craniometrical data can well predict the fact of Xinjiang populations to be the admixture between the east and the west. Among the Xinjiang populations, the Yanbulaq $\mathrm{M}$ in the east was in the Eastern Eurasian cluster, while Yanbulaq C from another graveyard in Yanbulaq was in the Xinjiang cluster, showing that the populations with different ancestries might have migrated into the same place. The Khotan was also very close to the Eastern cluster, indicating that Khotan might have more eastern components than most of the other Xinjiang populations.

The PCA map (Figure 3(b)) was similar to the MDS map, but displayed much clearer clusters. The East Asians were in the upper-left side of the map. The East European and Siberian populations were in the upper-right of the map. Two Central Asian populations were in the lower-right of the map. Therefore, the Western Eurasians were all in the right of the map. The Xinjiang populations were scattered between the Eastern and Western clusters. The Khotan was closest to the East Asians among the Xinjiang populations, especially in the first component.

We calculated the Pearson's $r$ distances using the former eight principal components (94.2\% of the variances), and transformed into a UPGMA (unweighted pair-group method with arithmetic means) tree (Figure 4). The tree was divided into two major clades, Eastern Eurasians and Western Eurasians. The Xinjiang populations were mostly in the Eastern Eurasians. Khotan, Yanbulaq, and Alwighul were even closer to the East Asians. However, the earliest Xinjiang sample, Qawrighul (1800 BC), was in the Western Eurasian cluster, indicating a western origin of this population.

\subsection{Admixture analysis}

To assess the contributions of the Eastern and Western Eurasians to the Xinjiang populations, we developed a statistic method to calculate the admixture proportions. The current most widely used admixture estimation program, STRUCTURE [33], are based on the individual data of the populations. However, almost all of the published ancient craniometrical data are average data of the populations, not the individual data. Therefore, STRUCTURE cannot be applied to these data. Although it is not perfect enough yet, our new method is based on the population average data that can be used to estimate the admixture. In the analysis, we assumed that there were two parental populations for the ancient Xinjiang people, i.e., Eastern Eurasians and Western Eurasians. We used the Anyang (Yinxu) sample as the Eastern reference and the Volga Pit Tomb sample as the Western reference. The results (Figure 5) were credible. The East Asian populations all exhibited high Eastern proportions (92.6\%-100\%), while the East European, Siberian, and Central Asian populations all exhibited very low Eastern proportions (0-23.3\%), which was consist with the common sense. The average Eastern proportion in the Xinjiang samples was $60.8 \%(34.4 \%-87.3 \%)$. Only three out of the 15 Xinjiang samples had less than $50 \%$ of the Eastern proportions. The Eastern proportion in the Khotan sample $(87.3 \%)$ was the highest among the Xinjiang samples, which was unpredictable. To verify this result, we changed different population samples as the parental references. The Eastern proportion in the Khotan varied from $78.7 \%$ to 91.2\%. This result indicated that our Khotan sample was more similar to the Eastern Eurasians. The high Eastern proportion in the Khotan might have resulted from the high Eastern contribution to the original Khotan population, or the subsequent genetic drift. 

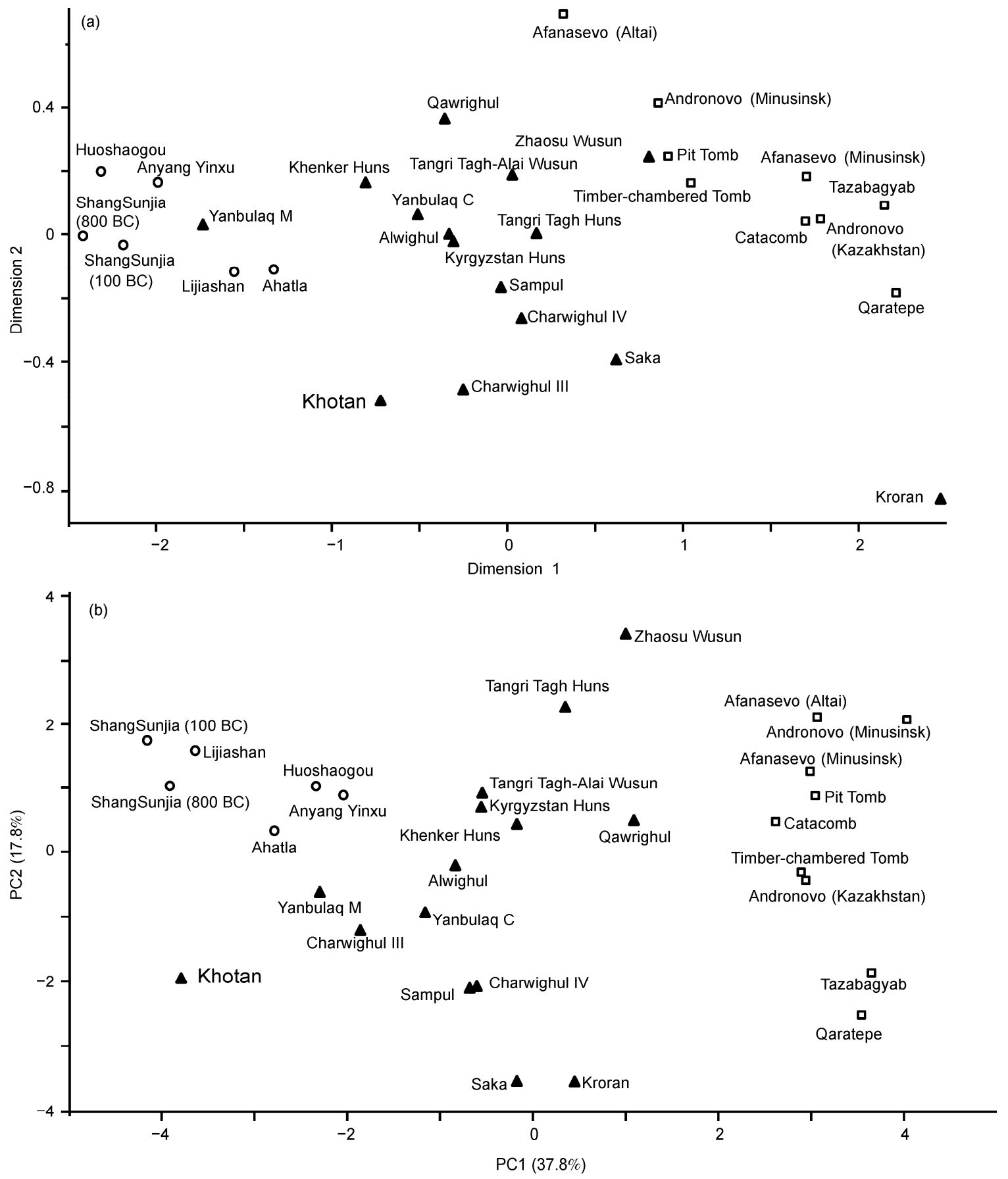

Figure 3 Multidimensional scaling (a) and principal component analysis (b) of craniometrical data of Khotan and surrounding ancient samples (males).

\section{Discussion}

\subsection{Inconsistency of ancestry identification by observa- tional features and by metrical traits}

The ancestry identification of the Khotan sample by observational features seemed inconsistent from that by metrical traits. Judged from the observational features, the Khotan samples were more like Western Eurasians, while they were more similar to the Eastern Eurasians in the metrical traits.
This phenomenon indicated that different data might issue different results during population relationship analyses. Some result may even be incompatible. This kind of incompatibility may have resulted from various reasons, including different genetic modes of the traits. However, very few genetic modes for the craniometrical traits have been decided, therefore, we cannot determine how different genetic modes influenced our results. One possible explanation can be that most metrical traits may be quantitative traits influenced by many genes, while observational fea- 
tures may be related to very few genes. For example, nasion depression followed a monogenic inheritance mode in pedigrees, and the western high nasion is dominant [34]. If most western features are dominant to the eastern features, the admixed population will be more like the western people, resulting in apparent bias. Differently, this bias will not appear when judged from quantitative traits. If the craniometrical traits are quantitative, the relevant results of population genetic structure will be more reliable. However, this hypothesis requires more genetic evidence.

\subsection{Khotan population was more similar to Eastern Eurasians}

Judged from the metrical data, especially from the PCA (Figures 3 and 4) and admixture analysis (Figure 5), the Khotan samples were obviously close to the populations from the Eastern and Central China. Among the Xinjiang populations, the Khotan was close to the Yanbulaq M and Charwighul III, and the later two populations had Eastern
Eurasian features with cranial characters of northeastern Tibetans $[18,25,27]$. Therefore, there were additional anthropological clues to the eastern ancestry of Khotan people.

Furthermore, archaeological evidence also supported an eastern influence of the Khotan, as well as influences from central Asia and Siberia. The styles of the pottery in Khotan were very similar to the Chust Culture found in Fergana Valley of Uzbekistan. However, geometric carving patterns on the Khotan pottery were most similar to those in Tibet and Qinghai. A single-eared gallipot found in Khotan can find an almost exact copy in the Qosgong graveyard, Lhasa, Tibet. There were also bronze wares excavated from Khotan. Those bronze wares had the same styles with those from Charwighul and Yanbulaq. The bronze or golden bellshaped eardrops from Khotan were most similar to those of the early Scythians from Siberia. Bronze harnesses and arrows with tailhooks were most similar to those of Arzan in Siberia [12]. Therefore, the population admixture in early Khotan had both physical anthropological and archaeological evidences.

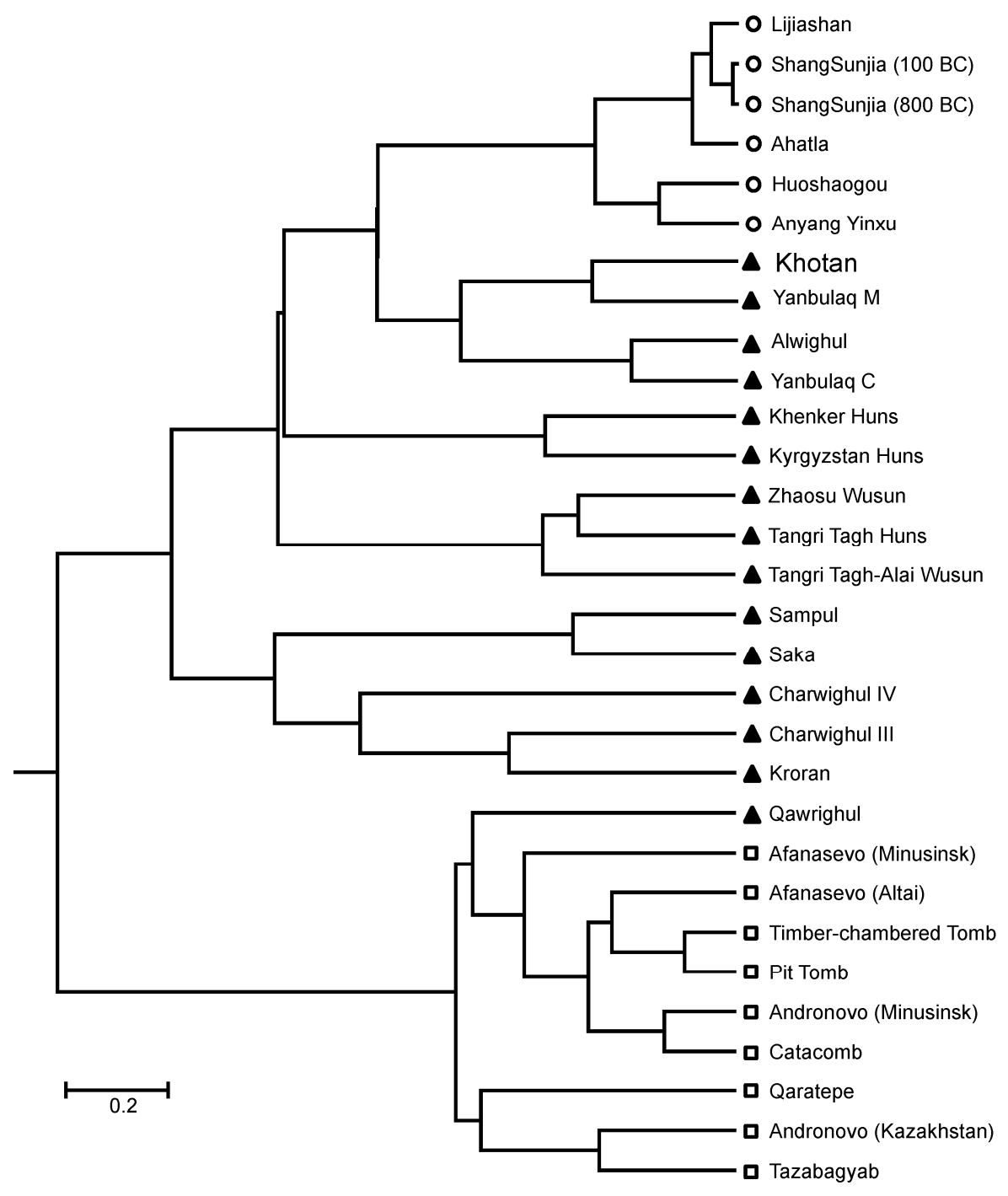

Figure 4 UPGMA cluster analysis of Pearson's $r$ distances among 30 male population samples. 


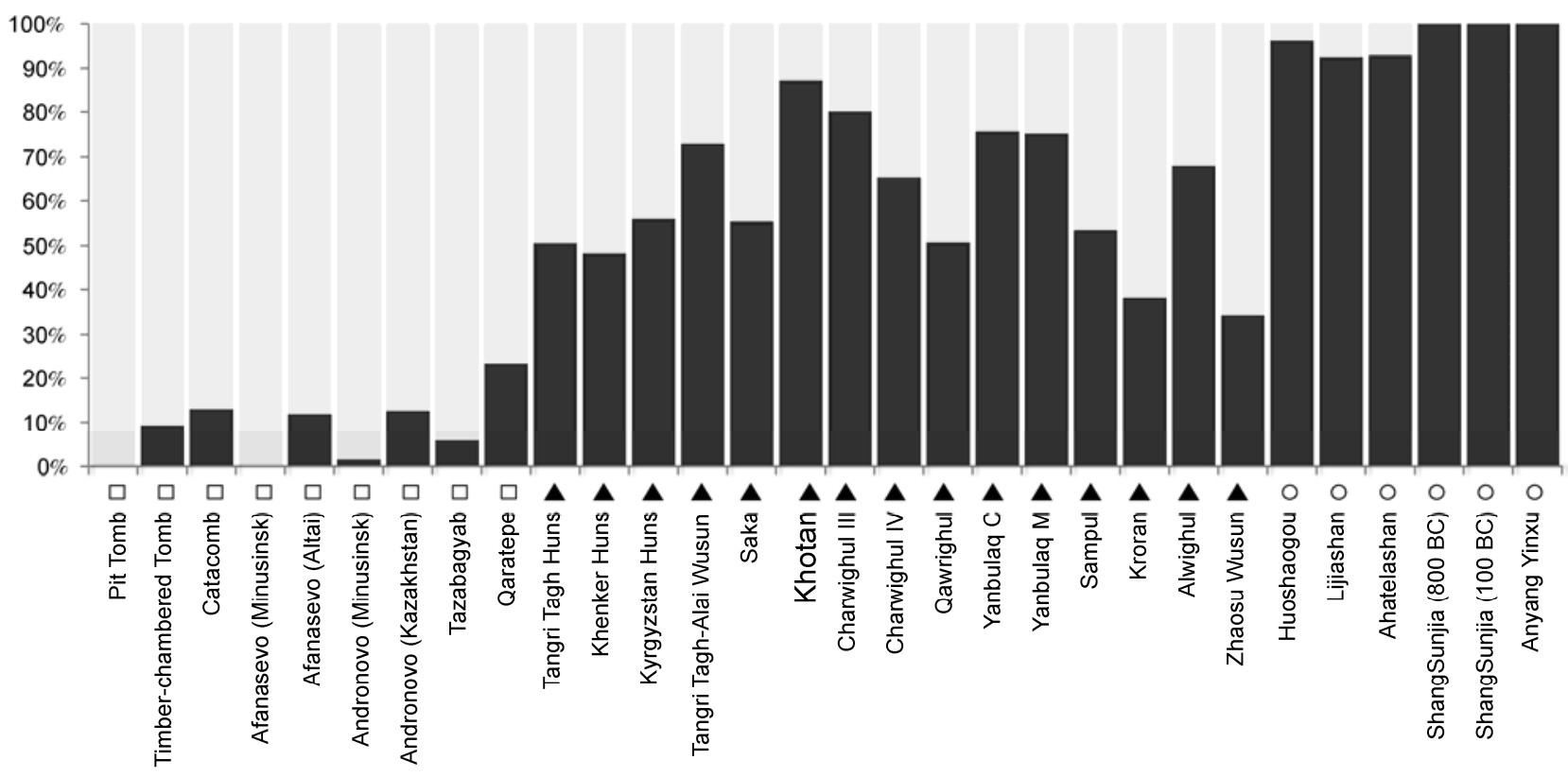

Figure 5 Population admixture analyses with Anyang as eastern parental reference and Volga (Pit Tomb) as western parental reference.

\subsection{Population admixture in ancient Xinjiang might be much wider}

Population admixture was widely found in the Bronze Age Xinjiang populations. The contributions were from East Asia, Central Asia, Siberia, etc. There were many Bronze Age population samples from East Asia which is close to Xinjiang, including Anyang Yinxu (1300-1027 BC), Huoshaogou (1600 BC), ShangSunjia (800-100 BC), Lijiashan (1550-690 BC), Ahatla (1550-710 BC). These Bronze Age populations were all similar to each other in cranial features and also similar to the modern northern Chinese and northeastern Tibetans [29-32]. The Siberian populations, including Afanasievo (3500-2500 BC) and Andronovo (2100-900 $\mathrm{BC})$, and the Volga populations, including Timber-chambered Tomb (1500-800 BC), Catacombs (2000-1500 BC, Pit Tomb (3600-2200 BC), were also variants of the Proto-Europeans. The Xinjiang Qawrighul (1800 BC) people were most similar to these populations $[19,30]$. The Central Asian populations, including Qaratepe (4000-3000 BC), Tazabagyab (2000-1000 BC), and Pamir Saka (600-400 BC), were called Mediterranean European, or Indo-Afghan [18]. Some Xinjiang populations were also similar to the Indo-Afghan type, including the Kroran (100 BC-100 AD), Sampul (100 BC-300 AD), and Shambabay (900-500 BC) $[18,20,22,23]$. However, those population samples all exhibited admixed features. For example, the one of the six Kroran samples showed very pronounced East Asian features, and very similar to the Kayue people in central China $[18,20]$. Moreover, the DNA analysis on the Kroran samples also revealed Eastern contribution [10].

Beside the Indo-Afghan type, there were also PamirFerghana type people in Central Asia. This type was mostly found in western Xinjiang. The Xinjiang Tangri Tagh-Alai Wusun (600-100 BC) showed most features of PamirFerghana type, but also some features of the Proto-Europeans. The Huns (Xiongnu) in western Xinjiang showed apparent admixture between eastern and western Eurasians $[18,21,26]$. Most of the Zhaosu Wusun people were Pamir-Ferghana type, while two females among them showed obvious East Asian features [18,21,26].

Sometimes, it seemed that two totally different populations were using the same graveyard. The most typical example was Yanbulaq (1300-550 BC) in eastern Xinjiang. Individual samples were divided into $\mathrm{M}$ group (East Asians) and C group (Proto-Europeans) [18,25]. In central Xinjiang, the admixture pattern was even complicated. A population sample in Toksun, Turpan, the Alwighul (600-200 BC), comprised Indo-Afghan, Pamir-Ferghana, East Asian, Proto-European, and intergraded types [18]. In southern Xinjiang, the early Charwighul IV (1000-500 BC) were most similar to the Proto-Europeans. The later Charwighul III (200 BC-220 AD) were more like East Asians, with three skulls showing characters of the Huns [18,27].

Totally, as was shown in the MDS and PCA of this study, all of the Bronze Age Xinjiang populations exhibited admixed features with more eastern contributions than western contributions. In the previous studies, very few samples from southwestern Xinjiang were studied. By this study, we know that the population admixture happened not only in eastern and northern Xinjiang, but also in the most southwestern part of Xinjiang. The eastern contributions to the Khotan samples might have come from Tibet. Furthermore, we suppose the populations to the west of Khotan might also be admixed, although relevant studies are yet to be done. 
This work was partly supported by the National Natural Science Foundation of China (31071102, 31071098, 30890034, 91131002), National Outstanding Youth Science Foundation of China (30625016), Natural Science Foundation of Shanghai (10ZR1402200), Philosophy and Social Science Foundation of Shanghai (2010BZH005), Shanghai Commission of Education Research Innovation Key Project (11zz04) and Shanghai Professional Development Funding (2010001)

1 Shirokogoroff S M. Anthropology of Northern China. Royal Asiatic Society. Shanghai: North China Branch, Extra Vol. 2, 1923

2 Ai Q, Xiao H, Zhao J, et al. A survey on physical characteristics of Uigur nationality (in Chinese). Acta Anthropol Sin, 1993, 12: 357365

3 Yao Y G, Kong Q P, Wang C Y, et al. Different matrilineal contributions to genetic structure of ethnic groups in the silk road region in China. Mol Biol Evol, 2004, 21: 2265-2280

4 Yang L, Tan S, Yu H, et al. Gene admixture in ethnic populations in upper part of Silk Road revealed by mtDNA polymorphism. Sci China Ser C-Life Sci, 2008, 51: 435-444

$5 \mathrm{Li} \mathrm{H}$, Cho K, Kidd J R, et al. Genetic Landscape of Eurasia and "Admixture" in Uyghurs. Am J Hum Genet, 2009, 84: 934-939

$6 \mathrm{Xu} \mathrm{S}$, Jin W, Jin L. Haplotype-sharing analysis showing Uyghurs are unlikely genetic donors. Mol Biol Evol, 2009, 26: 2197-2206

7 Tan J Z, Han K X. Physical characters and ethnic affiliations of several ancient nationalities in North China (in Chinese). Commun Contemp Anthropol, 2007, 1: 58-66

8 Mallory J P, Mair V H. The Tarim Mummies. New York: Thames \& Hudson, 2000

9 He H Q, Jin J Z, Xu C, et al. Study on mtDNA polymorphism of ancient human bone from hami of Xinjiang, China 3200 BP (in Chinese). Acta Anthropol Sin, 2003, 22: 329-337

$10 \mathrm{Li} \mathrm{C}$, Li H, Cui Y, et al. Evidence that a West-East admixed population lived in the Tarim Basin as early as the early Bronze Age. BMC Biol, 2010, 8: 15

11 Zhang F, Xu Z, Tan J, et al. Prehistorical East-West admixture of maternal lineages in a 2500-year-old population in Xinjiang. Am J Phys Anthropol, 2010, 142: 314-320

12 Xinjiang Archaeological Team, IA, CAS. Liushui Cemetery of the Bronze Age in Yutian County, Xinjiang (in Chinese). Kaogu (Chinese Archaeology), 2006, 7: 31-38

13 Alekseev V P, Debets G F. Craniometry: Methodology of Anthropological Research. Moscow: Science Press, 1964

14 Shao X Q. Handbook of Anthropometry (in Chinese). Shanghai: Shanghai Lexicographical Publishing House, 1985

15 Baba H. Anthropology Course, Supplement 1, Anthropometry II, Human Skeleton. Tokyo: Yuzankaku Press, 1991

16 Kolar J C, Salter E M. Craniofacial Anthropometry: Practical Meas- urement of the Head and Face for Clinical, Surgical, and Research Use. Springfield IL: C.C. Thomas, 1997

17 Ginzburg V V, Trofimova T A. Paleoanthropology of Central Asia. Moscow: Science Press, 1972

18 Han K X. The collected papers about the racial anthropological study of the ancient Silk Road inhabitants (in Chinese). Ürümqi: Xinjiang Renmin Chubanshe, 1993

19 Han K X. Anthropological characters of the human skulls from ancient cemetery at Qawrighul. Xinjiang (in Chinese). Acta Archaeol Sin, 1986, 34: 361-384

20 Han K X. Anthropological characters of the human crania from Kroran site, Xinjiang (in Chinese). Acta Anthropol Sin, 1986, 5: 227-242

21 Han K X, Pan Q F. Anthropological materials from Wusun tombs in Zhaosu, Xinjiang (in Chinese). Acta Archaeol Sin, 1987, 4: 503-523

22 Han K X. Racial characters of the human skulls from Sampul cemetery in LuoPu County, Xinjiang (in Chinese). Acta Anthropol Sin, 1988, 7: 239-248

23 Han K X. Human skulls from Shambabay cemetery in Tajik County (in Chinese). Xinjiang Wenwu, 1988, 1: 32-35

24 Shao X Z, Cui J, Yang Z J. The ancient human skulls from Shanpula commune of Lopu county, southern Xinjiang (in Chinese). Acta Anthropol Sin, 1988, 7: 26-38

25 Han K X. Anthropological material from the Yanbulaq site in Hami, Xinjiang (in Chinese). Acta Archaeol Sin, 1990, 38: 371-395

26 Han K X. Racial anthropological characters of Saka,Wusun, Huns and Turki (in Chinese). The Western Regions Studies, 1992, 2: 3-23

27 Han K X, Zhang J. The Study of Racial Characteristics of Human Skulls from Ancient Cemetery at Charwighul, Hejingcounty, Xinjing (in Chinese). Beijing: Ocean Press, 1997. 23-38

28 Wang M Z. Xinjiang Chawuhu-A Large-scale Clan Cemetery Excavation Report (in Chinese). Beijing: Oriental Press, 1999. 299-337

29 Han K X, Pan Q F. Study on the human bones from middle and small tombs in Anyang Yinxu. In: Yang X M, ed. Craniology of Anyang Yinxu (in Chinese). Beijing: Wenwu Press, 1984. 50-375

30 Zhang J. A racio-typological study of the human skulls from the cemetery of Kayue culture at Lijiashan, Qinghai (in Chinese). Acta Archaeol Sin, 1993, 3: 381-413

31 Han K X. A study of the human bones from the ancient cemetery on Ahatla Hill in Xunhua, Qinghai (in Chinese). Acta Archaeol Sin, 2000, 3: 395-420

32 Han K X, Tan J Z, Zhang F. The Racio-Anthropological Study on Ancient West-North Area, China (in Chinese). Shanghai: Fudan University Press, 2005

33 Pritchard J K, Stephens M, Donnelly P. Inference of population structure using multilocus genotype data. Genetics, 2000, 155: 945-959

34 Chen L, Li H, Xia Y M, et al. Genetic mode of nasal shape (in Chinese). J Fudan Uni Nat Sci, 2002, 41: 92-96

Open Access This article is distributed under the terms of the Creative Commons Attribution License which permits any use, distribution, and reproduction in any medium, provided the original author(s) and source are credited.

\section{Supporting Information}

Table S1 Individual craniometric data of Liushui graveyard in Khotan

Table S2 Frequencies of craniofacial observational features among the human remains of Khotan Liushui graveyard

Table S3 Hierarchical classification of craniofacial indices of Khotan Liushui graveyard

Table S4 Population comparison of the mean values of 17 craniofacial metric variables of males

The supporting information is available online at csb.scichina.com and www.springerlink.com. The supporting materials are published as submitted, without typesetting or editing. The responsibility for scientific accuracy and content remains entirely with the authors. 